\title{
Real-Time Control and Protection of the NEPTUNE Power System
}

\author{
Kevin Schneider Chen-Ching Liu* \\ Department of Electrical Engineering \\ University of Washington \\ Seattle, WA 98195 \\ *liu@ee.washington.edu
Tim McGinnis Bruce Howe
Applied Physics Lab
University of Washington \\ Harold Kirkham \\ Jet Propulsion Laboratory \\ California Institute of Technology
}

\begin{abstract}
The NEPTUNE power delivery system faces several challenges in serving the needs of the oceanographic community. Two major challenges, operating the system under normal conditions and protecting it against faults, require the development of new approaches unfamiliar to power engineers. In particular, the power management system must cope with several modes of potential system instability, and the protection system must operate in a deliberately weak system. Furthermore, it is likely that communications will be disrupted in the event of a fault. The approach taken to address these challenges is described.
\end{abstract}

\section{Introduction}

In the past, power limitations have restricted long term oceanographic studies to using only low power instrumentation. NEPTUNE seeks to relax the power constraint by extending the capabilities of the conventional terrestrial power delivery system grid into the Pacific Ocean $[1,2]$.

Terrestrial power systems are based on interconnected ac networks with parallel loads, while underwater telecommunications are dc point to point series systems. The proposed NEPTUNE power system is different from both. It is a highly interconnected dc system with parallel loads. It will consist of a $3000 \mathrm{~km}$ cabled sub sea network with two shore landings that will supply power at approximately forty-six locations, see Fig. 1.

Each of these forty-six nodes will provide a point of interconnection for scientific equipment, supplying both power and communications.

In order to maximize the deliverable power, the system will operate at $-10 \mathrm{kV}$ with respect to the ocean. The voltage supplied to the science load will be $400 \mathrm{~V}$ and $48 \mathrm{~V}$ via power converters.

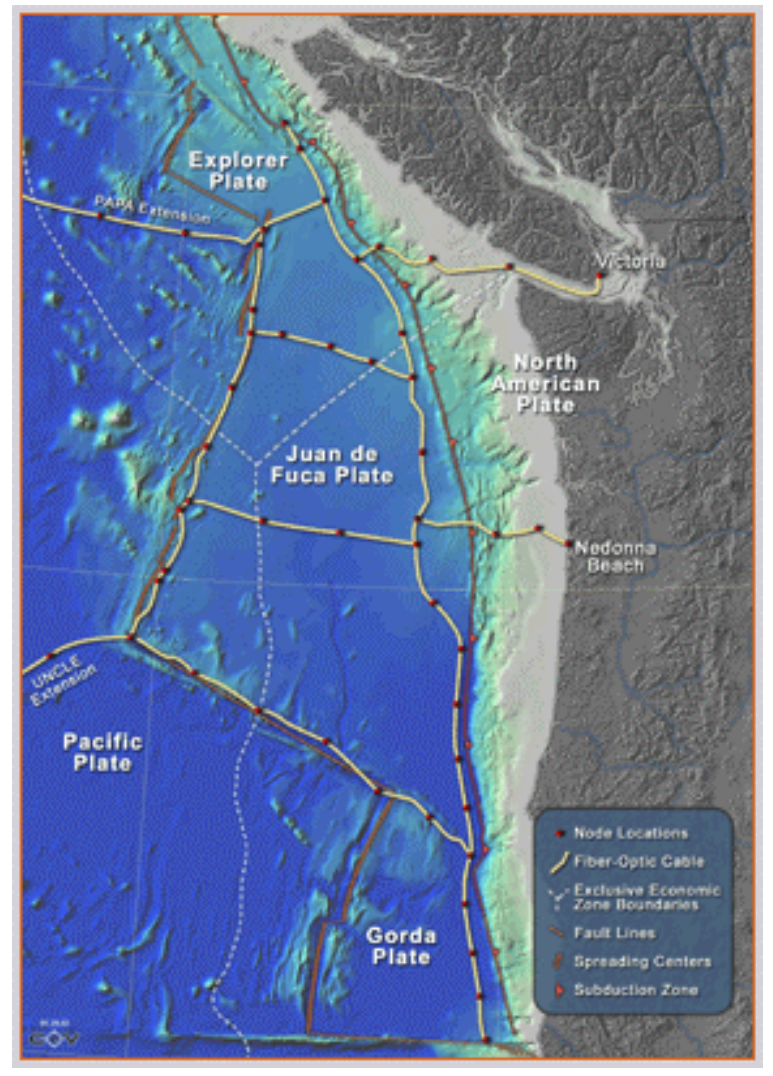

Fig. 1. The proposed NEPTUNE observatory in the northeast Pacific

Power is supplied to the system from two planned shore stations, one in Oregon and the other in British Columbia. The system will use a single conductor telecommunications cable, referred to as the backbone cable that requires a sea water return system. 


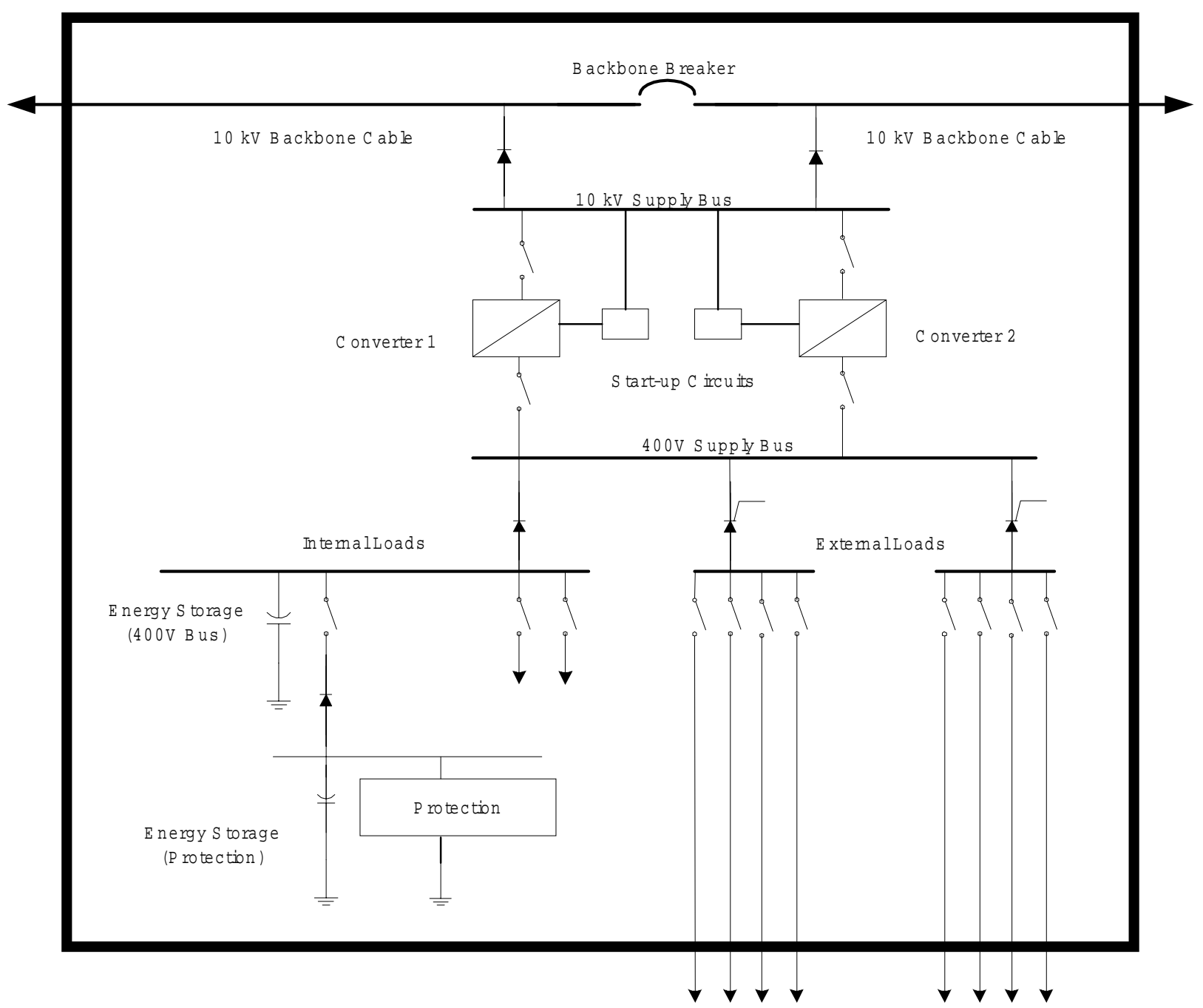

Fig. 2. Internal node arrangement

In order to supply power to the entire system, it is planned to energize nodes sequentially from shore. Once power is applied to the first off-shore node through the backbone cable, the main power converter start-up circuits are supplied through diodes (Fig. 2). The purpose of these diodes is to allow power to be supplied to the start-up circuits from either end of the backbone cable. This is necessary since the networked topology of the NEPTUNE system makes it impossible to specify in advance which side will be energized first. After approximately 10 seconds the start-up circuits causes one of the main power converters in the node to begin operation.

As soon as the main power converter is operating, the communications system begins its own start-up period. The communications start-up has a duration of between one and two minutes at each node. With the establishment of communications, the backbone breaker is closed and the next node can be energized. Once power and communications have been supplied to a node, external load can be supplied.

The backbone breaker is actually a complex system of several switches. When closing, a pre-insertion resistor will be used to limit the current through the breaker. This serves two purposes. First, it limits the volt-drop on the preceding cable that would be caused due to charging the capacitance of the next section. Second, it allows for the protection system to detect a cable fault before full power is applied. The full closing sequence will occupy only a few milliseconds.

By repeating this sequence, the NEPTUNE system can be completely interconnected. Since NEPTUNE is a network, it will be able to operate with multiple nodes and/or cables out of service. This feature of the power system will allow for reliable delivery of power.

It should be noted that during a normal start-up sequence, the backbone circuit breaker is not closed until communications is established with the shore-based power management system. Since the proposed communication system takes a minute or so to execute a cold start, the process of starting NEPTUNE may occupy several tens of minutes.

Should the communication system at a particular node fail, the power system controller in the node will (after some time) close the breaker without being so instructed from shore. It will enter what we are calling a "safe mode." 
Some of the protection system is operating, and as much as possible of the power system is energized.

During the time that nodes are being energized, a power management system ensures that the system is not being placed in an unstable condition. Stability must also be monitored during routine operation. Our approach is described next.

\section{Power Management}

Power flow, or load flow, calculations are the primary tool for calculation of the steady-state operating conditions of a power system. The power flow problem is non-linear, which increases the complexity of calculation. Several well known numerical methods are available for solution of the problem. The method adopted in this paper is the Newton-Raphson (N-R) method that has been widely used for conventional alternating current power systems.

Power flow for terrestrial alternating current power systems has been extensively studied and is well understood. Power flow for direct current systems is an area where relatively little work has been done, for this reason it will be addressed in this paper.

It should be noted that relative to the conventional power flow algorithms, the NEPTUNE power flow has the following advantages:

1) As it is a dc system, there are no reactive power considerations.

2) As it is a dc system, the inductance of all lines can be considered zero at stead y state.

3) DC systems have no voltage angles to calculate.

Together these factors indicate that all that needs to be solved for is the voltage at each bus, based on real power injections into the system. The node voltage $\mathrm{V}_{\mathrm{i}}$ at iteration $\mathrm{N}+1$ is given by equation:

$$
\mathrm{V}_{\mathrm{i}}^{\mathrm{N}+1}=\mathrm{V}_{\mathrm{i}}^{\mathrm{N}}-\left(\mathrm{J}\left(\mathrm{V}_{\mathrm{i}}^{\mathrm{N}}\right)^{-1}\right) * \mathrm{f}\left(\mathrm{V}_{\mathrm{i}}^{\mathrm{N}}\right)
$$

where:

$\mathrm{V}^{\mathrm{N}}=$ Voltage at beginning of the iteration.

$\mathrm{V}^{\mathrm{N}+1}=$ Voltage at end of the iteration.

$\mathrm{f}\left(\mathrm{V}^{\mathrm{N}}\right)=$ Power flow equations.

$\mathrm{J}\left(\mathrm{V}^{-1}\right)=$ Jacobian of the power flow equations.

In the above equation, the mismatch at bus $\mathrm{i}$ is given by:

$\mathrm{f}_{\mathrm{i}}\left(\mathrm{V}^{\mathrm{N}}\right)=\mathrm{P}_{\mathrm{Li}_{\mathrm{i}}}-\mathrm{P}_{\mathrm{i}}=\mathrm{P}_{\mathrm{Li}_{\mathrm{i}}}-\mathrm{V}_{\mathrm{i}} \sum_{1}^{\mathrm{n}} \mathrm{Y}_{\mathrm{ik}} \mathrm{V}_{\mathrm{k}}$

where:

$\mathrm{P}_{\mathrm{Li}}=$ The injection of power into bus $\mathrm{i}$. $\mathrm{n}=$ Number of nodes
In the initial iteration, $\mathrm{V}^{\mathrm{N}}$ where $\mathrm{N}$ is assumed to be 1 for the initial iteration, all buses are assumed to have 1 per unit voltage, which corresponds to $10,000 \mathrm{~V}_{\mathrm{DC}}$. This is used as the basis to calculate the new voltages, $\mathrm{V}^{\mathrm{N}+1}$, at each of the nodes in the system. These new values are then designated as $\mathrm{V}^{\mathrm{N}}$ and the process repeats. Convergence is achieved when the mismatch $f\left(V^{N}\right)$ is reduced to within a prespecified tolerance. To ensure accuracy of the calculations, the stopping point for the iterative scheme was set by the sum of the (absolute value of) differences of voltages at all buses, instead of just one reference bus, from one iteration to the next. Using the difference of voltages at all buses tends to increase the number of iterations required for convergence, this however is not a major concern since the NEPTUNE system is small and the computation times short.

When the load on the power system is increased, there comes a point at which the load flow problem ceases to have a solution, the calculation will not converge. This is easily illustrated by considering a situation in which there is a constant voltage source supplying a load through a transmission line (Fig. 3). Figure 3 shows a condition where a constant voltage source delivers power to a constant power load. As the value of the constant power load is set at higher levels, more current must flow across the line, lowering the received voltage.

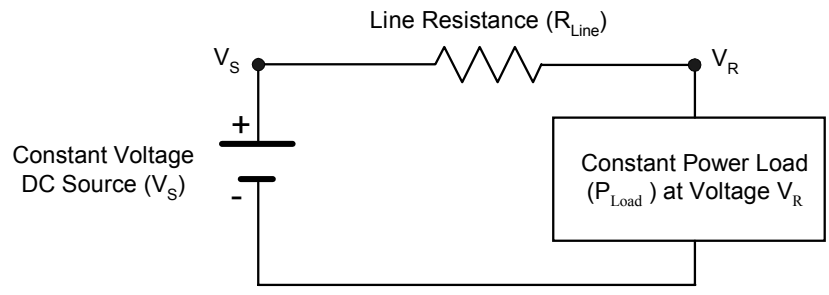

Fig. 3. Transmission line model

The voltage at the receiving end of the line, for a given source voltage and load power, is given by:

$$
\mathrm{V}_{\mathrm{R}}=.5 *\left(\mathrm{~V}_{\mathrm{S}} \pm \sqrt{\mathrm{V}_{\mathrm{S}}^{2}-4 \mathrm{P}_{\mathrm{L}} \mathrm{R}_{\mathrm{L}}}\right)
$$

where:

$$
\begin{aligned}
& \mathrm{V}_{\mathrm{R}}=\text { Voltage at the receiving end } \\
& \mathrm{V}_{\mathrm{S}}=\text { Voltage at the sending end } \\
& \mathrm{P}_{\text {Load }}=\text { Power of the load } \\
& \mathrm{R}_{\mathrm{Line}}=\text { Resistance of the line }
\end{aligned}
$$

In Fig. 4, the voltage is plotted as a function of the load power. As with the power flow calculations, the P-V curve is well known for ac system but is seldom applied to dc systems. 


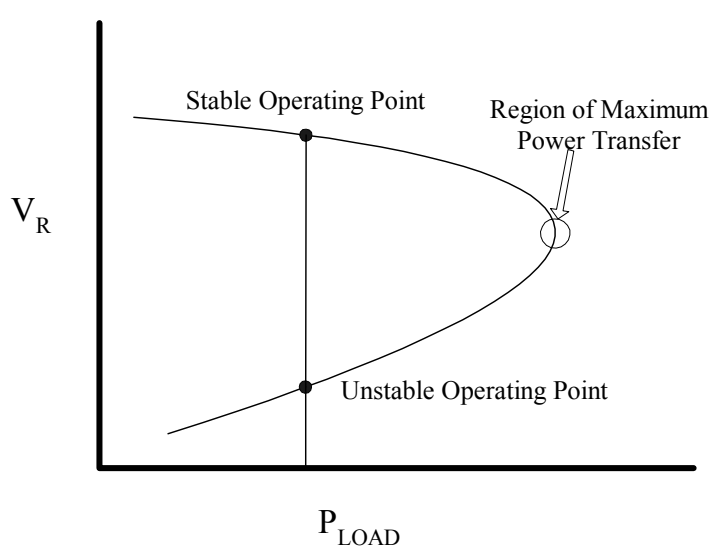

Fig. 4. P-V curve

Since Equation 3.3 is quadratic, there is a possibility of zero, one, or two solutions for a given load power. Only the stable operating point is physically realizable.

The point of maximum power transfer marks the maximal power beyond which power flow solution ceases to exist. This corresponds to the point in ac systems at which voltage collapse occurs [6].

Extensive simulations have shown that voltage collapse is not a major concern, in the initial design, for the NEPTUNE power system because the shore station converters are incapable of delivering sufficient power. (At present it is proposed that the shore stations be rated at 100 $\mathrm{kW}$ each.) In the present design, the total load capability of the sub-sea converters is around $920 \mathrm{~kW}$, assuming operation of both converters in a node, far larger than the capability of the delivery system. Because the rated shore station output power may be increased at some future time, voltage collapse is being studied now to determine what the non-constrained system limits are.

Voltage collapse may also become an important issue when the power system is operated in other than fully networked topologies. For example, when the system is operating without the Oregon shore station, the maximum power capability of the system (limited by voltage collapse considerations) is $1.93 \mathrm{~kW}$ at each node. This figure is within the capability of the Victoria shore station, the limiting factor is the voltage collapse limit.

Monitoring the power system to ensure that the operating constraints are met is the task of the proposed Power Monitoring and Control System (PMACS). The software functions of PMACS are shown in Fig. 5.

Through the communication systems, status data (for example, breaker status) and analog measurements (voltage, current, and power measurements) are acquired and archived by PMACS. If all operating constraints (voltage, current, and power limits) are satisfied, the system is in a Normal state. In case any of the operating constraints are violated, the system is in an Emergency state. The actions taken by PMACS in these states are discussed below. If service to loads has been interrupted due to a fault and the fault has been cleared, a system restoration procedure must be followed. This is also described below.

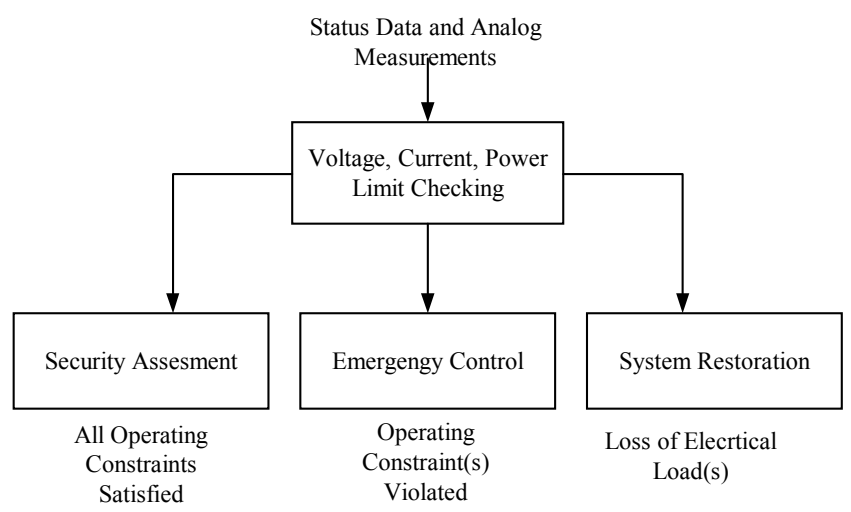

Fig. 5. Power Monitoring And Control System (PMACS)

\section{A. Monitoring and Emergency Control}

PMACS has Supervisory Control And Data Acquisition (SCADA) capabilities. (The SCADA system is a common remote monitoring and control system for electric power systems.) Remote control capabilities are needed so that the shore station can initiate necessary switching actions such as remedial actions to alleviate an overload or abnormal voltage condition.

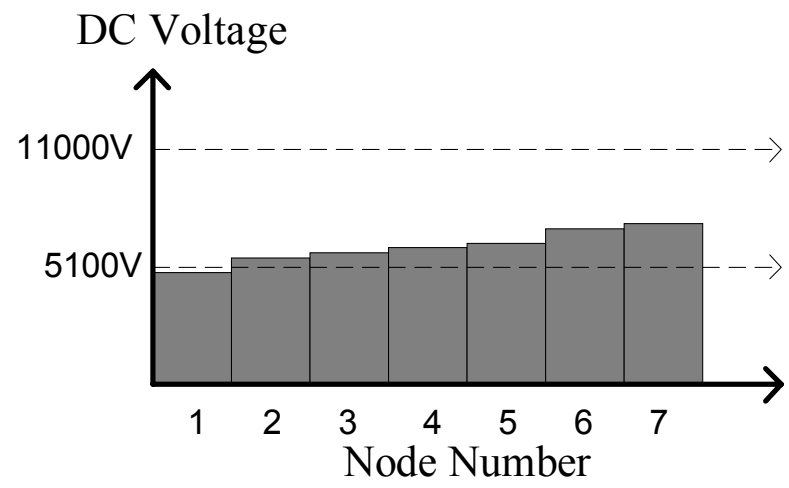

Fig. 6. Allowable voltage band

Because the resistance of the cable proposed for NEPTUNE is large, voltage drops from the shore station to the remote locations will be significant. While each dc-dc converter has an internal control loop to regulate its load voltage, it is designed to shut-down if the input voltage drops below 5,100 V. (Note that this action would help preclude voltage instability, as system voltages around 0.5 p.u. indicate the onset of such instability.) PMACS will monitor the node voltages and determine if it is necessary to adjust the source voltages or the loads so that the voltage profile along the cable system remains within an acceptable range at all times. An unacceptable voltage profile is 
illustrated in Fig. 6 which shows the system voltages at nodes 1 thru 7, the seven southern most nodes in Fig. 1 with node one being furthest south, when the average load on each node in the system is $4.9 \mathrm{~kW}$. In order to obtain the results in Fig. 6 converter dynamics were not considered, i.e., the load was not reduced to zero when the converter input voltage dropped below $5100 \mathrm{~V}$.

The shore station will acquire voltage and current measurements from all nodes of the backbone once every second. The PMACS software will perform limit checking to detect any voltage violations or over-current problems. If any abnormal condition is detected, the emergency control actions are determined by the PMACS at the shore station. The emergency control actions can include adjustment of the shore station voltages or load shedding.

The algorithm to calculate the emergency control actions has yet to be developed. While load shedding would only be used as a last resort, the NEPTUNE power system will categorize loads. At present four categories are anticipated:

1. Essential loads are crucial to safe system operation. These loads are generally internal to the node, for example, the communication system.

2. High-Priority loads warrant extra effort to keep them energized. This is likely a category that includes temporary designations, as events in the observatory change. General loads will be temporarily designated High-Priority if the scientific interest warrants it.

3. General loads will receive no particular effort to keep energized, nor will they be early on the list of loads that can be shed. Most science loads are expected to be in this category.

4. Deferrable loads are candidates for disconnection as the system approaches peak power. Lighting and battery-charging systems are likely to be in this category.

\section{B. Security Assessment}

PMACS will have a security assessment module. Security is a measure of the power system's ability to withstand a contingency, such as a short circuit or the loss of a shore station. Figure 7 shows how the PMACS security assessment module categorizes situations. Normal conditions can be divided into two categories: secure and insecure. In both of these cases the system is operating with no operating limits violated and all load being supplied. The difference between the two categories is how they compare with respect to a pre-selected list of contingencies. (The contingency list has not yet been selected.)

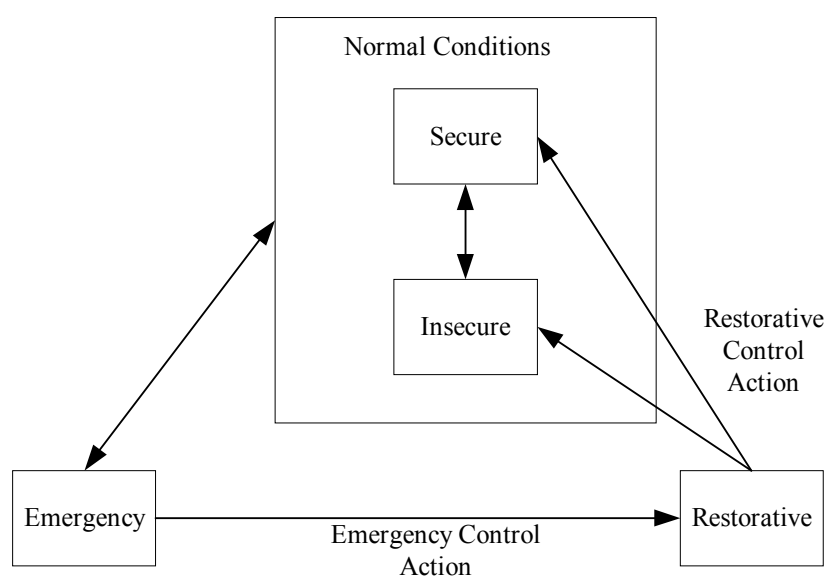

Fig. 7. Security assessment

To be in a secure operating state the system must meet all system operating requirements at the present time, as well as meeting all requirements if a fault from the contingency list occurs. If the system meets all requirements at the present time but would violate a limit should a fault from the contingency list occur, the system is insecure. In both cases, secure and insecure, all system loads are supplied.

During an emergency condition operating constraints are not met. The violation of operating constraints could be in the form of a low voltage or a high current. From the emergency state the system can either move back to a normal condition, where all constraints are satisfied, or progress to a restorative condition where load has been lost. At this point the restoration component of PMACS is activated.

\section{Restoration}

Even though the NEPTUNE power system will be equipped with a fast-acting protection system, shut-down of much of the network's science load may be unavoidable in the event of a fault. This is because the shore stations voltage will automatically (and rapidly) drop in order to achieve current limiting. Consequently, many of the dc-dc converters will stop operating. Since it is not planned to have a large amount of energy storage as part of the sub-sea system, widespread outages of science loads will unavoidably result. Therefore, after the system has finished responding to a fault (i.e., the protection system has operated to isolate the fault), some parts of the system that are not faulted will have to be brought back on-line. In the worst case, the entire system will require re-start.

A better restoration system would minimize the time to recover from a fault. To accomplish this, some means of re-starting the entire system at the same time would be needed. A re-start would then be a fundamentally different process from a normal start-up. Such a restoration system is being designed. 


\section{Protection}

A utility power system typically delivers power to its customers with a high level of reliability. This level of reliability has not been achieved through a lack of power system faults. Instead, it is achieved through redundancy of parts and an attitude of "if it can go wrong, it will." This attitude has led to the use of $\mathrm{N}-0, \mathrm{~N}-1$, and $\mathrm{N}-2$ reliability criteria. These criteria refer to the number of power system components that are lost before a loss of load is experienced. N-1 and N-2 are generally accepted for the interconnected transmission systems. Distribution systems, due to their radial nature, tend to be reliable only for $\mathrm{N}-0$, i.e. no component failures! We would like to build NEPTUNE to meet N-1 reliability criteria, that is to be able to serve load even if some part of it is out of service.

The goal of the proposed protection system is to disconnect a faulted cable section or a component, without affecting the remainder of the system.

From the beginning, it has been clear that the NEPTUNE power system will be different from a conventional power system in many ways. The major problem from the aspect of protection has been the issue of a "weak system". When a fault occurs on the NEPTUNE power system, the voltage rapidly collapses across a large portion of the system. Node power converters cease to function, with the result that there is no longer a source of power for the protection relays at those nodes.

In a terrestrial system, each major substation contains banks of lead acid batteries that act as a source of stored energy for the protection relays. In NEPTUNE, it is not feasible to include large banks of lead acid batteries. While alternatives are being evaluated, it is presently thought that it will not be possible to accommodate sufficient energy storage to allow for many of the conventional protection relaying schemes.

The three areas in the NEPTUNE system that require protection are:

- the $10 \mathrm{kV}$ backbone system,

- the internal node components

- the $400 / 48 \mathrm{~V}$ low voltage distribution system.

These areas will be discussed separately.

\section{A. Backbone Protection}

In order to protect the backbone cable against shunt faults, a redundant relaying approach is proposed. The two redundant methods are differential current and distance relaying.

Differential current relaying works on the principle of that the total current entering one end of a cable should equal the total current leaving from the other end. If there is no load connected between the two ends, this condition is violated only when there is a fault. See Fig. 8. Since there is a latency associated with travel time of information from one node to the next, all current measurements are time stamped so that the correct data are being compared. One of the great advantages of the differential current protection is that it provides discrimination for high impedance faults.

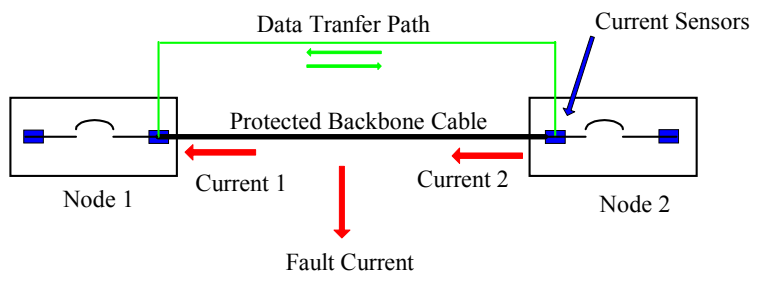

Fig. 8. Differential current protection

Distance relaying works on the principle of measuring the resistance of the cable. At each point in a node where a backbone cable penetrates the pressure case, voltage and current measurements are made (Fig. 9), so that the value of resistance can be determined. In a normal operating condition, this value is greater than the resistance of the cable section. During a fault condition, assuming a zero resistance fault, the resistance value seen from the source drops, and can be used to estimate the distance to the fault location. For most utility applications the reach of distance relays is set to $80 \%$ of the distance to the next breaker and relaying point. A value less than $100 \%$ is used so that a fault close to the far end of the section, but on the other side of the next breaker, will not cause 2 breakers to trip. The accuracy in estimating the distance will be limited to the accuracy of the current and voltage sensors and the fact that the sensors are measuring transient waveforms

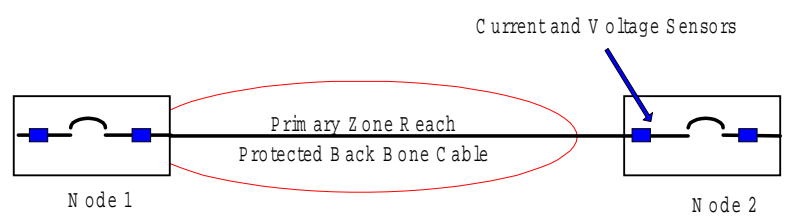

Fig. 7. Distance protection, set to around $80 \%$

\section{B. Node Protection}

Protection against faults within a node is easier than it is for the backbone cable. The reason for this is the physical proximity of components. Differential protection is feasible using no more complex a communication system than a meter or so of wire.

For example, even though the typical NEPTUNE node has 3 wires associated with its backbone circuit (incoming $10 \mathrm{kV}$, outgoing $10 \mathrm{kV}$ and a ground), the current in these 3 can be added in a device called a dc current comparator, and even a small discrepancy can be detected. One of the tasks of the NEPTUNE Power Group will be to develop a low-cost comparator for sub-sea use.

While a comparator will detect a ground leakage within the node, detecting a fault inside a converter is more 
difficult. Conversion of voltages from the varying $10 \mathrm{kV}$ backbone level to the constant $400 \mathrm{~V}$ and $48 \mathrm{~V}$ science voltages amounts to a transformer action, where the transformer ratio is not fixed. Thus, instead of current comparison, power comparison will be used to relay the converters. The method of power comparison requires both current and voltage measurements, and requires that the power lost in the converter as thermal losses be taken into account. While converter efficiency varies from approximately $92 \%$ to $94 \%$ depending on loading, we feel that the problem is solvable.

\section{Concluding Remarks}

This paper represents the continuation of work that has been in progress for over a year. A major contribution made by this paper is the outline given for both the power management and protection components of the NEPTUNE power system.

Analysis has shown what the limits of voltage stability of NEPTUNE are and PMACS has been designed to work within these limits. In addition to the normal operation, provisions have been made for PMACS to control the system during emergency conditions and to restore lost sections of the system after faults have occurred.

A protection system has been proposed that will operate quickly in order to isolate faults in the minimum possible time in order to minimize unnecessary loss of load.

There is still a great deal of work that remains to be done before the ideas presented here can be implemented in an operating system. Examples are: What will be the voltage limits for emergency control? What faults will be on the security assessment list for contingencies? What will be the exact protection relay settings? What amount of energy storage is required in a node to ensure continuous operation of the protection system?

These questions, and several others, will be the center of the research that will lead to the final design of a power system that is capable of supporting the NEPTUNE system.

\section{Acknowledgment}

This research is sponsored by National Science Foundation through the grant titled, "The NEPTUNE Plate-Scale Observatory: The Power System," OCE-0116750.

\section{References}

[1] B. Howe, H. Kirkham, and V. Vorperian, "Power System Considerations for Undersea Observatories," IEEE J. Oceans Eng., Vol. 27, No. 2, April 2002, pp. 267-274.

[2] B. Howe, H. Kirkham, V. Vorperian, and P. Bowerman, "The Design of the NEPTUNE Power System," Proc. Oceans, 2001, MTS/IEEE Conference and Exhibition, Vol. 3 , 2001, pp. 1374-1380.

[3] J. Delaney, G. R. Heath, A. Chave, H. Kirkham, B. Howe, W. Wilcock, P. Beauchamp, and A. Maffei, "NEPTUNE Real-Time, Long-Term Ocean and Earth Studies at the Scale of a Techtonic Plate," Proc. Oceans 2001, MTS/IEEE Conference and Exhibition, Vol. 3, 2001, pp. 1366-1373.

[4] A. R. Maffei, A. D. Chave, G. Massion, S. N. White, J. Bailey, S. Lerner, A. Bradley, D. Yoerger, H. Frazier, and R. Buddenberg, "NEPTUNE Gigabit Ethernet Submarine Cable System," Proc. Oceans 2001, MTS/IEEE Conference and Exhibition, Vol. 3, 2001, pp. 1303-1310.

[5] C. C. Liu, S. J. Lee, and S. S. Venkata, "An Expert System Operational Aid for Restoration and Loss Reduction of Distribution Systems," IEEE Trans. Power Systems, May 1988, pp. 619-626.

[6] K. T. Vu, C. C. Liu, C. W. Taylor, and K. M. Jimma, "Voltage Instability: Mechanisms and Control Strategies," Proceedings of the IEEE, Volume 83, Issue 11, Nov. 1995, pp. $1442-1455$. 